\title{
O jogo da entrega: uma análise semiótico-estilística de anúncios publicitários
}

\author{
Fernanda Trindade Leite ${ }^{\mathrm{i}}$ \\ Maria de Fatima Carvalho Queiroga ${ }^{\mathrm{ii}}$
}

\section{RESUMO}

Durante o primeiro ano da pandemia da COVID-19, empresas do ramo de aplicativos de delivery tiveram um protagonismo forte no coração do consumidor: o contato físico precisava ser evitado, mas a entrega de alimentos não poderia esperar. Buscando persuadir o público-alvo por meio das emoções geradas pela pandemia, as empresas Ifood, Rappi e Uber Eats fizeram uso de repertórios lexicais, cores, fontes e imagens na construção dos textos multimodais para acionar no imaginário do alocutário esses sentimentos. Formulamos a hipótese de que as escolhas com alto potencial icônico foram as responsáveis por criar imagens mentais que despertassem esses sentimentos. Analisamos ainda, à luz de estudos semióticos e estilísticos, como esses sentidos foram explorados pelos aplicativos de delivery no contexto pandêmico.

Palavras-chave: Texto Multimodal; Anúncio Publicitário; Iconicidade Verbal; Estilística.

\begin{abstract}
During the first year of SARS-CoV-2 pandemic, companies of delivery applications business played a strong role in the consumer's heart: physical contact needed to be avoided, but food delivery could not wait. Looking for persuading the target audience by the feelings caused for the pandemic, the companies Ifood, Rappi and Uber Eats used lexical choices, colors, fonts and images to build multimodal texts to activate in consumers imaginary these feelings. We formulate the hypothesis that the choices with high iconic potential were responsible for creating mental images that arouse these feelings. We also analyze, in the light of semiotic and stylistic studies, how these meanings were explored by delivery applications in the pandemic context.
\end{abstract}

Keywords: Multimodal Text; Advertisement; Verbal Iconicity; Stylistic.

\footnotetext{
${ }^{\mathrm{i}}$ Mestranda em Letras pela UERJ. Pesquisadora da área de descrição da língua portuguesa. ORCID: https://orcid.org/0000-0003-3533-584X / feletribrito@gmail.com

ii Mestranda em Letras pela UERJ. Pesquisadora da área de ensino de língua portuguesa. ORCID: https://orcid.org/0000-0001-8852-4340 / prof.mariaqueiroga@gmail.com
} 


\section{INTRODUÇÃO}

O mundo de hoje é o mundo da comunicação, cujos símbolos são, a todo momento, manipulados. A busca inesgotável de formas para seduzir o consumidor, no entanto, não se consolidou apenas nos campos da indústria e do comércio. Todos os setores de negócios aderiram à lógica da economia moderna, direcionando uma boa quantia de seu lucro para o setor de "marketing". O que antes era somente divulgação, passou a ser persuasão e fez emergir do mundo dos antigos reclames um novo conceito de publicidade. Esse conceito comporta muitas técnicas de convencimento, associando imagem e palavra de formas cada vez mais criativas na composição dos textos multissemióticos que compõem os anúncios publicitários.

A beleza, a criatividade, a novidade, o inusitado e o lúdico tornaram-se peças inestimáveis nas propagandas, levando o consumidor a admirar o trabalho dos "marqueteiros" e, consequentemente, a considerar a compra do produto ou o uso dos serviços por eles anunciados. No entanto, o público-alvo só se tornará um consumidor se o anúncio for bem redigido e usar a palavra como signo condutor das informações pretendidas, que deverão ser decodificadas por esse público de acordo com suas experiências.

Assim, partindo do pressuposto de que "o mundo é um construto semiótico e de que tudo que nos rodeia é convolável em signo, portanto, sujeito a semioses múltiplas ou mesmo infinitas" (SIMÕES, 2019, p. 76), levantamos a hipótese de que, com signos com alto potencial icônico, os anúncios analisados constroem os sentidos pretendidos. Para isso, analisaremos qualitativamente os níveis de iconicidade e a produção de sentidos em uma amostra de anúncios publicitários de aplicativos de delivery no contexto devastador da pandemia da Covid-19 no Brasil. A análise estilística recairá, sobretudo, sobre os estudos do teórico Charles Bally (1865-1947) - doutrinador da estilística da língua (langue) -, uma vez que o que se busca é a descrição textual; enquanto a análise semiótica será pautada na Teoria da Iconicidade Verbal de Simões (2009), a fim de analisarmos os signos com alto potencial icônico nos anúncios.

A estilística e a sintaxe se farão cruciais para uma análise mais completa dos fenômenos linguísticos e expressivos que dão harmonia e sentido ao texto. As construções das frases também serão apresentadas pelo viés da sintaxe e da iconicidade 
diagramática. Além disso, o uso dos verbos no modo imperativo será analisado a fim de mostrar o quanto os tradicionais e persuasivos verbos nesse modo têm dado lugar a novas estruturas sintáticas e o quanto os anúncios se reinventam de acordo com o contexto.

$\mathrm{Na}$ esteira dos componentes do processo comunicativo, serão abordadas as características do texto injuntivo e a função conativa da linguagem, nas construções multimodais dos textos publicitários, como importantes unidades comunicativas para a análise da construção das frases dos anúncios selecionados. O intuito é mostrar a sintaxe que compõe a estrutura de alguns atos de fala e que, porventura, possa subverter a sua intenção comunicacional.

Com esses pressupostos e premissas, analisaremos como as escolhas de signos icônicos atuaram nas estratégias persuasivas de anúncios das empresas de entrega Ifood, Rappi e Uber Eats, veiculados nas redes sociais em suas respectivas contas verificadas do Instagram desde o início da pandemia da Covid-19 no Brasil (março de 2020), atingindo seu público-alvo, a saber, pessoas de todas as idades e classes sociais que estão em isolamento social.

\section{FUNDAMENTAÇÃO TEÓRICO-METODOLÓGICA}

A iconicidade é uma propriedade semiótica fundada na plasticidade propriedade da matéria de adquirir formas sensíveis por efeito de uma força exterior. Tal atributo pode ser estendido ao plano abstrato, pela imaginação do leitor, compondo imagens de entes e seres reais ou fictícios (SIMÕES, 2003, p. 42). Assim sendo, tornase possível aplicar a iconicidade em níveis concretos e abstratos. No nível concreto, verificam-se as iconicidades diagramática, sintagmática e paradigmática dos sistemas sígnicos dos quais resultam (dicionários e gramáticas atuam como reguladores dessa relação concreta, no plano linguístico); no nível abstrato, as modalidades imagética e metafórica, ou seja, operações subjetivas decorrentes de interpretações dos interpretantes, sejam eles indivíduos ou coletivos individualizados nas culturas que representam. Daí a pertinência de um estudo da iconicidade no plano da estilística, com anúncios publicitários com ampla intertextualidade cultural. 


\begin{abstract}
A semiotização dos objetos culturais se mostra como condição para o entendimento das interações sociais e para o aperfeiçoamento das relações humanas. Quando se fala de descrição e de interpretação do mundo e da realidade, impõe-se pensar em processos sígnicos por meio dos quais são construídos os cenários e as práticas sociais. Semiótica, Filosofia e Linguagem formam o tripé indispensável da evolução dos modelos sociais. Por meio dessas ciências, o homem pode aprofundar seu autoconhecimento e o conhecimento do mundo que o cerca e das consequências dos relacionamentos humanos em todos os níveis (SIMÕES, 2019, p. 12).
\end{abstract}

A partir disso, observamos a importância de trazermos à baila análises de textos midiáticos sob o viés semiótico-estilístico, já que o estilo parte intrinsecamente da complexidade do ser humano e do seu potencial intelectivo e linguístico. Martins (2012, p. 19), em seu livro Introdução à estilística, traz a seguinte citação de Guiraud: "estilo é o aspecto do enunciado que resulta de uma escolha dos meios de expressão, determinada pela natureza e pelas intenções do indivíduo que fala ou que escreve".

Ainda sobre o conceito de estilo, Câmara (1978, p. 14 ) afirma que a estilística vem completar a gramática a partir do pressuposto de que o estudo do estilo é a face da linguística que nos faltava. Por meio de um sistema linguístico de representações intelectivas, o sujeito falante também satisfaz seus impulsos de expressão.

A análise estilística vai além de compreender e interpretar semanticamente um texto, ela desnuda as palavras e revela os mecanismos linguísticos expressivos que garantem uma escrita bem articulada. Nesse sentido, é importante que esteja claro que o fato estilístico é tanto de ordem psicológica e social quanto linguística.

Para Bakhtin, estilo é o conjunto de procedimentos de acabamento de um enunciado. [...] isso significa que o estilo é o conjunto de traços fônicos, morfológicos, semânticos, lexicais, enunciativos, discursivos etc. que definem a especificidade de um enunciado e, por isso, criam um efeito de sentido de individualidade (BAKHTIN apud FIORIN, 2018, p. 51).

Neste interim, os textos serão analisados no nível estilístico descritivo, baseando-se na teoria da estilística da língua, fundada por Bally. Sobre essa vertente estilística, Martins (2012, p. 21) afirma que "Bally se ocupa da descrição do equipamento expressivo da língua como um todo"; para ele, a língua é um repertório de possibilidades, cujos falantes manuseiam conforme suas necessidades de expressão. Bally se fundamenta na língua como expressão afetiva do pensamento, como se vê na obra Introdução à Estilística. 
Charles Bally volta-se para os aspectos afetivos da língua falada, da língua a serviço da vida humana, língua viva, espontânea, mas gramaticalizada, lexicalizada e possuidora de um sistema expressivo cuja descrição deve ser a tarefa da estilística (BALLY apud MARTINS, 2012, p. 20).

Nossa análise estilística será pautada nas construções sintáticas de algumas frases selecionadas de anúncios de delivery das empresas Ifood, Rappi e Uber Eats. Seguir a cartilha do anúncio tradicional, com o uso do verbo no imperativo, num momento em que a concorrência é ferrenha, pode não ser uma boa estratégia, já que a irreverência e a inovação potencializam o alcance do público jovem. Com base nisso, a análise das construções frasais se faz pertinente para escamotear as intenções recônditas dos anúncios e para trazer à tona essa arquitetura frásica que sai da tradicional estética imperativa dos anúncios e dá lugar, por exemplo, a orações subordinadas substantivas predicativas reduzidas de infinito.

No texto publicitário, a articulação entre a linguagem verbal e a linguagem não verbal contribui de forma relevante para a significação global do texto. Por isso, o estudo semiótico-estilístico em textos cuja estética se sobreponha ao conteúdo precisa ser mais minucioso, uma vez que o estilo é signo estruturante da expressão verbal. A partir disso, depreende-se que a interpretação de um texto multimodal de natureza publicitária exige um entendimento para além do domínio verbal, já que tais textos possuem componentes de efeitos estilísticos da expressão verbal que ultrapassam a função utilitária (informar, narrar, descrever, discutir). Assim, é de extrema importância reconhecer o plano da expressividade da língua, sua intangibilidade e sua complexidade, sobretudo nesses textos multimodais, que são compostos por múltiplas naturezas sígnicas.

Analisaremos, então, a partir dos estudos estilísticos e da iconicidade verbal, uma seleção de anúncios capazes de revelar que o uso de metáforas e interdiscursividades multimodais, as escolhas lexicais e as construções sintáticas exploradas de formas semelhantes nas três empresas de Delivery, que manifestam marcas expressivas (icônicas) e impressivas (indiciais), atuam nos sentidos do públicoalvo a fim de persuadi-lo. O recorte temporal das propagandas contempla o período do início da pandemia - março de 2020 - até março de 2021, primeiro ano da pandemia da Covid-19 no Brasil. A motivação desse lapso temporal se dá pela valorização dessas empresas neste momento pandêmico em que o mundo está inserido, uma vez que as 
pessoas necessitam cada vez mais permanecerem em suas casas, aumentando as vendas em domicílio.

\section{ANÁLISE DO CORPUS}

\subsection{Iconicidade lexical}

Nesta seção, observaremos a combinação entre as escolhas lexicais, os itens que compõem a linguagem não verbal dos anúncios e as figuras de linguagem presentes, tais como: cores, imagens, metáforas, neologismos, além de intertextualidades multimodais e todo o processo de criação de significações na composição das mídias.

Destacamos que os anúncios que serão analisados a seguir foram retirados do perfil do Ifood no Instagram (@ifoodbrasil). Vejamos:

Figura 1- Campanha \#pedeumdogão

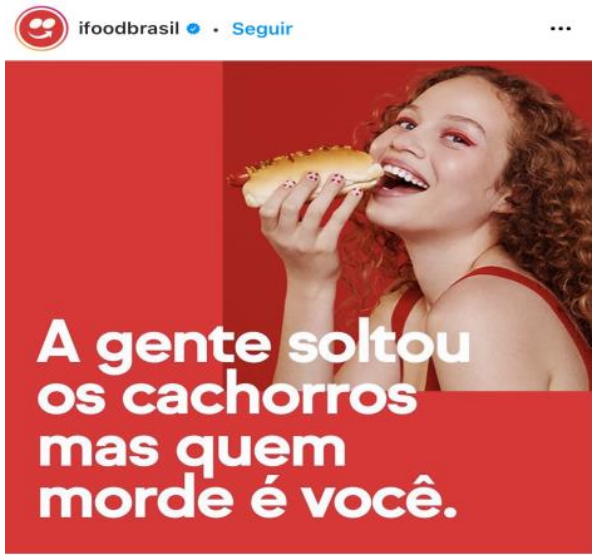

Figura 2- Campanha \#pedeumdogão

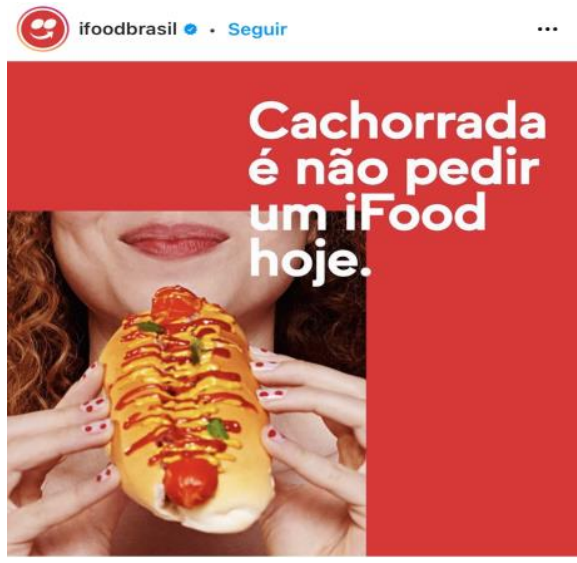

Fonte de ambas as figuras: Instagram @ifoodbrasil, 09 de setembro de 2020.

Figura 3- Campanha \#arraiáifood

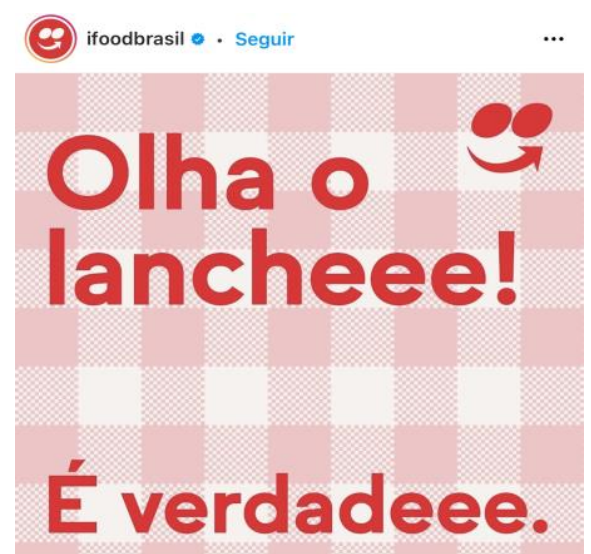


Na Figura 1 e 2, o entendimento do texto verbal só é possível a partir da relação que estabelece com a imagem da modelo prestes a comer o cachorro-quente que leva próximo à boca. A cor vermelha no fundo da imagem, cor quente muito explorada em anúncios de produtos alimentícios, lembra ingredientes utilizados no próprio alimento: a carne e o molho de tomate.

$\mathrm{Na}$ figura 1, esses elementos que compõem o texto não verbal do anúncio esclarecem a intertextualidade que ocorre no texto verbal: "a gente soltou os cachorros" dialoga com a expressão popular "soltar os cachorros", com a diferença de que os cachorros aqui são os sanduíches. Na tabela abaixo, separamos os itens léxicos desse primeiro anúncio, com seu valor icônico (que também pode ser indicial), para mostrar como representam o texto-fonte. Vejamos:

\begin{tabular}{|l|l|l|}
\hline \multicolumn{1}{|c|}{ Item léxico } & Valor icônico no texto-fonte & Valor icônico no anúncio \\
\hline Soltou (soltar) & Perigo & Liberdade \\
\hline Cachorros & Inimigo & Alimento \\
\hline Morde & Dor & Prazer \\
\hline
\end{tabular}

Notamos que a quebra de expectativa gerada pela conjunção "mas" é capaz de desfazer as primeiras imagens criadas na mente do leitor pelos itens léxicos da segunda coluna vertical e transportá-lo às representações possíveis a partir dos léxicos da terceira coluna do nosso quadro. Assim, a construção com uma oração coordenada adversativa é responsável pela mudança no valor icônico dos signos destacados, gerando uma subversão.

Na figura 2, a expressão "cachorrada é" aciona na mente do leitor que o fato de não pedir um Ifood significaria que ele estaria excluído de uma proposta imperdível. 


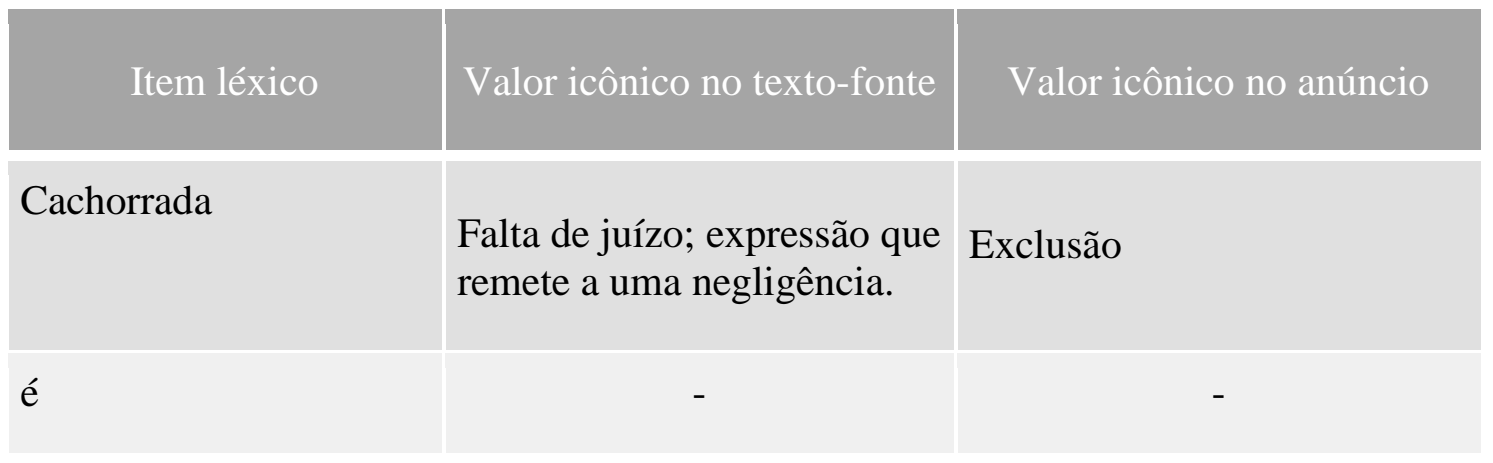

A expressão "cachorrada" também faz uma analogia ao alimento que denominamos "cachorro-quente".

Na Figura 3, observamos uma intertextualidade multimodal. São signos que configuram essa intertextualidade à imagem de fundo, à repetição do "e" nas palavras "lanche" "verdade" e à construção sintática das duas orações. Tais signos e a construção sintática estabelecem uma relação com o texto-fonte, a saber, a cantiga tradicional das festas juninas que traz os versos “olha a cobra! / é mentira!”. Temos, portanto, exemplos de iconicidade lexical e iconicidade diagramática no mesmo anúncio. Vejamos a tabela:

\begin{tabular}{|l|l|l|}
\hline \multicolumn{1}{|c|}{ Item léxico } & Valor icônico no texto-fonte & \multicolumn{1}{|l}{ Valor icônico no anúncio } \\
\hline Olha & Cuidado & $\begin{array}{l}\text { Aciona na memória do leitor } \\
\text { o começo da cantiga. }\end{array}$ \\
\hline Cobraaa / Lancheee & Perigo & Prazer \\
\hline Mentiraaa / Verdadeee & Alívio & Alívio \\
\hline
\end{tabular}

A imagem quadriculada no fundo do "banner" é índicial, pois faz lembrar a toalha de mesa também quadriculada tipicamente usada nas festas caipiras. Já em "lancheee" e "verdadeee" temos a repetição da vogal que também aparece na cantiga de festa junina "olha a cobraaa! / é mentiraaa!", apresentando uma comutação dos fonemas. Essa repetição também ocorre oralmente na cantiga com as palavras "cobra" e "mentira". Observamos também que, além da comutação, há uma proposital oposição estabelecida entre "mentira" e "verdade". 


\subsection{Estilística lexical}

A partir do momento que se compreende que estilo é um fator recorrente, que diferencia e individualiza o ser humano, torna-se mais fácil garimpar os efeitos de sentido que a expressividade proporciona ao texto.

Segue a análise abaixo:

Figura 4 - Campanha \#viverÉ

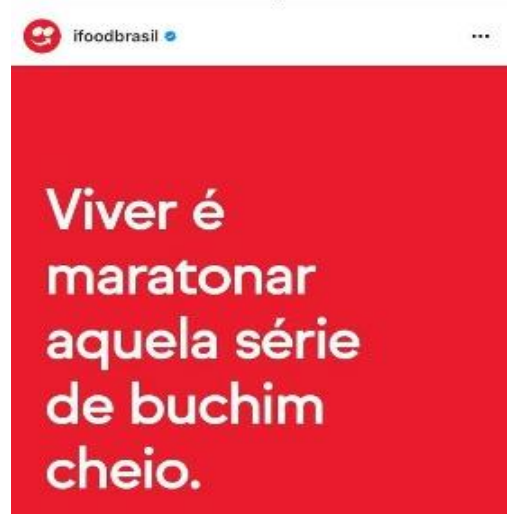

Fonte: Instagram @ifoodbrasil, 29 de outubro de 2020.

Propaganda original: "Viver é maratonar aquela série de buchim cheio".

Oração desenvolvida: "Viver é para quem maratona aquela série de buchim cheio".

Observam-se as palavras "maratonar" e "buchim", tratam-se respectivamente de um neologismo e de um truncamento do diminutivo. O termo "maratonar" é proveniente do substantivo maratona, que significa uma corrida realizada na distância oficial de 42 km. A partir dessa lógica, tal termo se consagrou entre os jovens por se referir à ação de assistir por horas intermináveis a séries em uma plataforma de streaming. "Maratona" aqui não tem sentido de esforço, gerador de cansaço; pelo contrário, refere-se ao conforto, gerador de descanso, que ficar assistindo "àquela série" por bastante tempo proporciona. É comum que as pessoas façam uma ligação entre comida e alguma atividade de entretenimento que lhes causem conforto, por isso, torna-se propício que as propagandas influenciem na permanência dos clientes no aconchego do seu lar, assistindo a algum serviço de "streaming" enquanto comem. Quanto mais 
"maratonarem" a séries, mais seus "buchinhos" ficarão cheios e mais lucratividade dará ao Ifood.

Já a expressão "buchim cheio" refere-se à barriga cheia, não tem uma função depreciativa ou pejorativa, o que ocorre é o mecanismo de encurtamento lexical do diminutivo que se dá por meio de operações morfológicas e discursivas. Num contexto interacional, essa forma mais coloquial, conotativa e íntima de dizer tem, na sua intenção comunicativa, o intuito de aproximar-se do interlocutor. A denotação não é detentora de todo sentido que há, e a conotação está aí para confirmar isso. É a linguagem conotativa que encontra amplo espaço nos anúncios publicitários, pois é capaz de introduzir subjetividade como nenhuma outra forma de linguagem é. O anúncio gira em torno de alcançar as pessoas que, por sua vez, são alvos fáceis da subjetividade e da afetividade que resultam da conotação. Baudrillard (1968, p. 229) confirma isso quando diz que "A linguagem publicitária é conotação pura, e o discurso é sempre alegórico".

A mensagem publicitária pode se apoiar no sentido denotativo ou no sentido conotativo. No primeiro caso, se concentrará no referencial, dando ênfase ao nome, à analogia e à informação; no segundo, se sustentará no implicativo, dando ênfase ao caráter, à analogia, à conivência, mais do que à informação propriamente dita (PÉNINOU, 1972, p. 210).

Os termos "descontinhos", "inteirinho" e "buchim", retirados das propagandas acima, estão no diminutivo não para significar algo de pequeno porte, mas para indicar afetividade. Segundo Henriques (2018, p. 55), “[o] que a estilística linguística tem como alvo é a sistematização dos meios que a língua nos oferece para exteriorizarmos nossas necessidades afetivas, isto é, os elementos emocionais que acompanham o enunciado".

No que se refere ao verbo no infinitivo "viver", é importante frisar que tanto sua incidência quanto seu significado trabalham juntos para dar o efeito pretendido. Segundo Martins (2012, p. 97) “[a] estilística léxica estuda os aspectos expressivos das palavras ligados aos seus componentes semânticos e morfológicos, os quais, entretanto, não podem ser completamente separados dos aspectos sintáticos e contextuais”.

Nesse contexto, nunca se preocupou tanto em viver, haja vista o número desastroso de mortes diárias que o brasil vem sofrendo pela Covid-19. As inúmeras repetições desse verbo no infinitivo (mais de 30 vezes, entre vídeos e fotos) têm a função, além de influenciar o interlocutor a como se viver, de resgatar o sentimento que, 
para muitos, está perdido devido às circunstâncias atuais, o sentimento da vontade de viver.

\begin{abstract}
Os elementos emotivos que entram na constituição do sentido das palavras são de máximo interesse para a estilística. A tonalidade afetiva de uma palavra pode ser inerente ao próprio significado ou pode resultar de um emprego particular, sendo perceptível no enunciado em razão do contexto... (MARTINS, 2012, p. 107).
\end{abstract}

Para Martins (2012), o emprego da linguagem figurada é um importante fator da afetividade, principalmente, em se tratando da metáfora, cujas palavras assumem um sentido mais afastado do significado fundamental. Independente do grau de expressividade, a metáfora indica a pretensão do autor em atribuir emoção e vivacidade às palavras. É o que acontece nos exemplos abaixo:

Figura 5- Campanha \#viverÉ



Figura 6- Campanha \#viverÉ

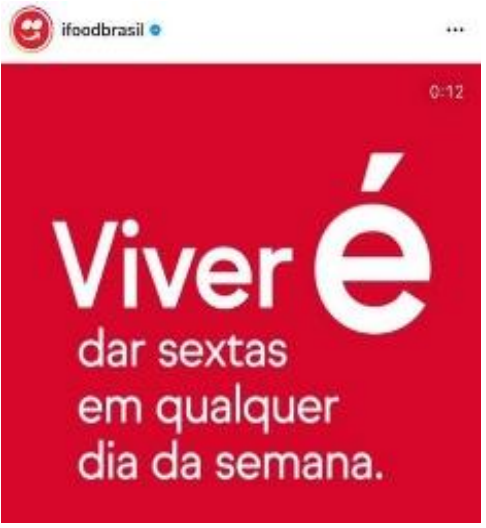

Fonte de ambas as figuras: Instagram @ifoodbrasil, 26 de janeiro de 2021.

A empresa se utilizou do recurso da homofonia dos substantivos "cestas" e "sextas" para metaforizar a segunda frase. No primeiro exemplo, está explícito que sabe viver quem dá cestas de presente em qualquer dia da semana. No segundo exemplo, há uma metáfora que perpassa a expressão "dar sextas", pois se observa que a referência desses termos recai sobre o neologismo "sextar", em "viver é sextar em qualquer dia da semana."

Feita a análise estilística da empresa Ifood, serão analisados agora alguns recursos estilístico-gramaticais observados nos anúncios das empresas UberEats e Rappi. 
Figura 7- Compras grandes



Peça suas compras grandes!
Figura 8- Compras grandes

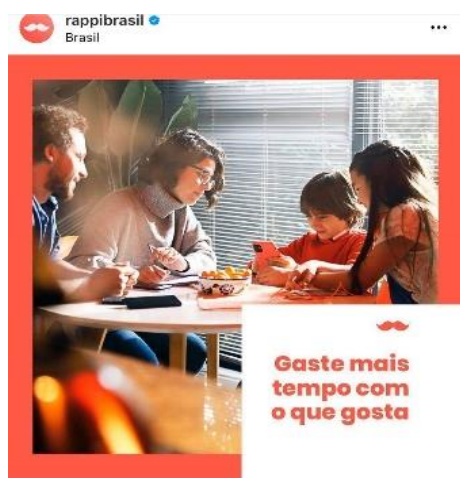

Figura 9- Compras grandes

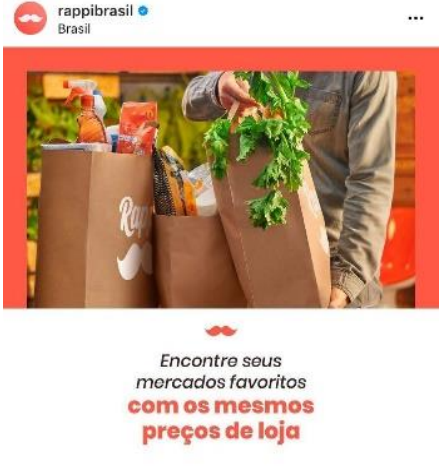

Fonte de ambas as figuras: Instagram @ rappibrasil, 06 de agosto de 2020.

Figura 10- Ocasiões especiais

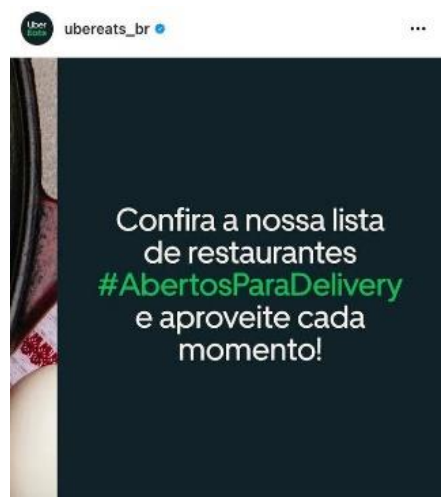

Figura 11- Ocasiões especiais

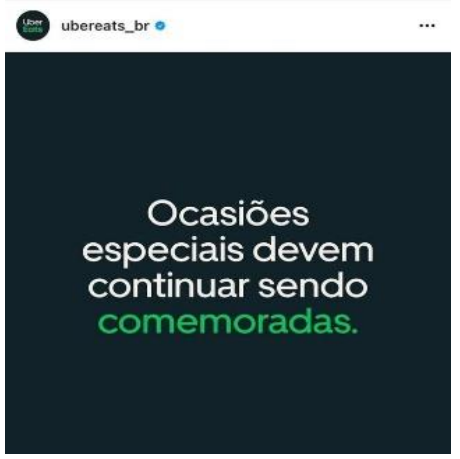

Figura 12- Páscoa

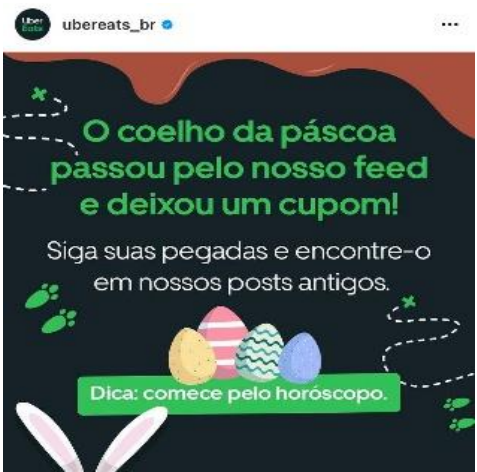

Fonte de ambas as figuras: Instagram @ubereats_br, 18 de maio e 02 de abril de 2020.

É importante frisar que a análise concomitante das duas empresas acima se deve pela semelhança no arcabouço estilístico-gramatical. Diagnosticou-se uma correlação no processo estrutural dos anúncios de ambas as empresas, de modo que se faz mais objetiva essa análise dual.

Diante dos modos de organização do texto, no que se refere ao gênero, observam-se com clareza características do texto injuntivo. Segundo Azeredo (2018, p. 95; p. 236), "a injunção consiste no emprego de formas da língua com que o enunciador explicita sua intenção de levar o destinatário, ouvinte ou leitor, a praticar atos ou ter atitudes". Ele destaca as formais verbais imperativas - "...o modo imperativo, que se usa em frases com que o enunciador expressa uma ordem, uma exortação, um pedido..." - 
como uma importante e a mais comum aliada na construção de um texto injuntivo e, também, como alicerces para esse gênero textual.

Numa abordagem comparativa entre as duas empresas, percebe-se o uso do famoso "coringa" dos enunciados, o tradicional verbo no modo imperativo, recurso linguístico muito usual nos anúncios publicitários. Se repetido muitas vezes, é visto como um mantra, uma fórmula mágica que tem a função de invadir o sistema cognitivo, afetar e direcionar os desejos e as atitudes do público-alvo, como no exemplo clássico do famoso comercial da Garoto que repercutiu muito nos anos 1990: "Compre batom, compre batom, compre batom...”.

Outrora, o recurso dos verbos no imperativo foi usado exaustivamente pelas mais diversas marcas do mercado, e a tradição de sua utilização em propagandas publicitárias se perpetuou. A influência insidiosa de como essa forma verbal arrebata o público-alvo é uma realidade incontestável, a sua funcionalidade é visível e sentida com base no retorno lucrativo de muitas marcas investidoras em marketing.

Segue abaixo uma análise dos verbos no modo imperativo:

\begin{tabular}{|ll|}
\hline 1. & "Peça suas compras grandes". \\
\hline 2. & "Gaste mais tempo com o que gosta". \\
\hline 3. & "Encontre seu mercado favorito com os mesmos preços de loja". \\
\hline 4. & "Confira a nossa lista de restaurantes e aproveite cada momento!" \\
\hline 5. & "Ocasiões especiais devem continuar sendo comemoradas". \\
\hline 6. & “....siga suas pegadas e encontre-o em nossos posts antigos". \\
\hline
\end{tabular}

Nos períodos acima, não se percebe uma riqueza de jogos de palavras nem figuras de linguagem que saltem aos olhos, os excertos são objetivos e sugestivos. Com exceção dos períodos 4 e 6 que são compostos por coordenação, estabelecendo uma relação de adição, os demais períodos são simples e objetivos.

Destaca-se o uso dos verbos no modo imperativo: "peça", "gaste", "encontre", "confira", "devem" e "siga" que compõem os anúncios das empresas de forma tradicional, mas não menos funcional do que outras estruturas de anúncios. Azeredo 
(2018, p. 236) elucida que “[...] as formas verbais do imperativo são invariáveis quanto ao tempo", tal maneira atemporal de comunicação tem a função de impulsionar os anúncios.

\begin{abstract}
As formas do indicativo e do subjuntivo se empregam em todas as funções da linguagem, já as do modo imperativo são exclusivas dos usos da língua em que o enunciador se dirige explicitamente ao seu interlocutor e frequentemente o nomeia pelo emprego de um vocativo, o que limita a ocorrência do imperativo à função conativa da linguagem (AZEREDO, 2018, p. 236).
\end{abstract}

O uso demasiado desses verbos em propagandas e a reverberação que ele proporciona são claramente explicadas pelo professor Azeredo, pois a predileção de tal uso pelos anunciantes, muitas vezes de forma inconsciente, também se dá pela exclusividade de seu uso em textos que se comunicam diretamente com o público-alvo, com a nítida finalidade de persuadi-lo.

Como um importante componente do processo comunicativo, essencialmente em anúncios publicitários, não se pode deixar de citar a função da linguagem conativa:

\footnotetext{
A função conativa é própria dos enunciados com que o emissor elege o destinatário como principal fator do processo de comunicação, agindo discursivamente sobre ele, como nas perguntas, nos conselhos, nas ordens. A função conativa perpassa nosso cotiado, já que boa parte de nossos atos de linguagem se destina a produzir comportamentos dos nossos interlocutores. Um dos domínios técnicos mais propícios ao exercício da função conativa da linguagem é a publicidade, cujo alvo é o cliente ou o consumidor (AZEREDO, 2018, p. 76).
}

A escolha das empresas em preservar a perpetuação dos verbos no imperativo é legítima, o novo assusta, e, muitas vezes, pode não funcionar. No entanto, nos anúncios da empresa Ifood, observamos que uma exploração da elasticidade da linguagem e do poder de inovação que ela proporciona pode ser uma boa estratégia para sair do básico e usual e atingir números maiores de pessoas.

\title{
2.3. Principais itens lexicais com alto potencial icônico
}

Foram encontradas algumas seleções lexicais com alto potencial icônico nas publicações das três empresas. Tais escolhas representam o perfil do produto anunciado 
e o serviço de entrega em domicílio; são elas: "entrega" e "pedido". Dentro dos anúncios, observamos que esses signos verbais protagonizaram metáforas e intertextualidades que foram responsáveis pelo teor criativo da produção do anúncio.

Vejamos abaixo um exemplo de cada uma dessas escolhas lexicais:

Figura 13- Campanha de dia das mães \#nossaEntrega


\section{Figura 14- Entrega}

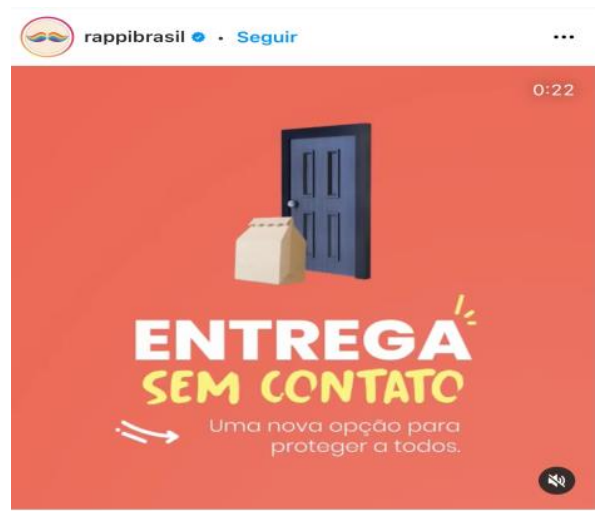

Fonte: Instagram @ifoodbrasil, 07 de maio de 2020. Fonte: Instagram @ rappibrasil, 26 de março de 2020

Figura 15- Entrega

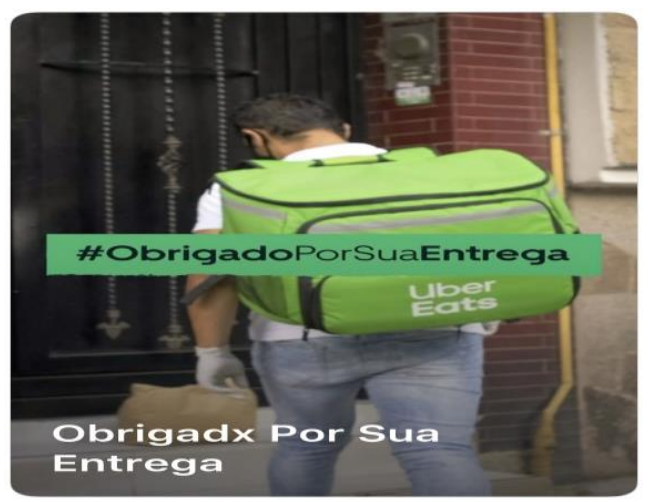

Figura 16- Campanha \#ViverÉUmaEntrega

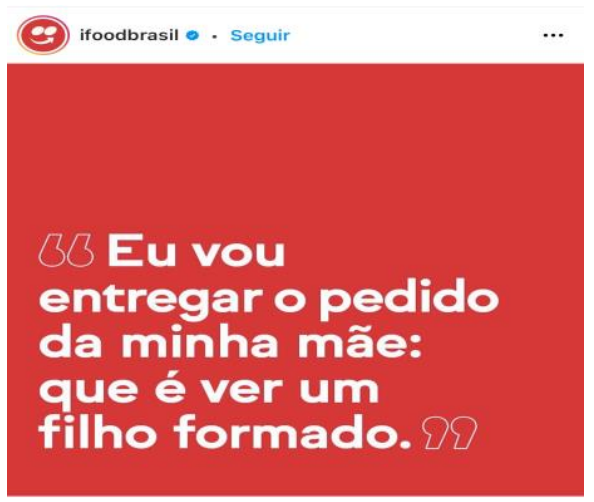

Fonte: Instagram @ubereats_br, 17 de abril de 2020 Fonte: Instagram @ifoodbrasil, 23 de julho de 2020. 
Figura 17- Delivery

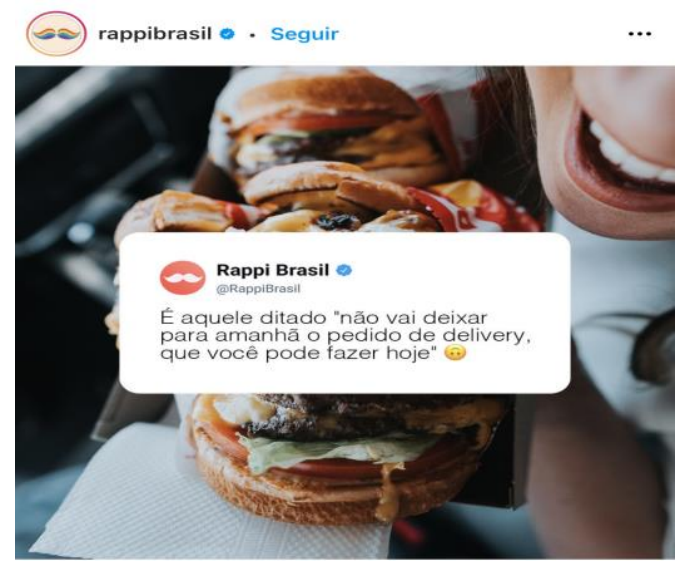

Figura 18- Contribuição

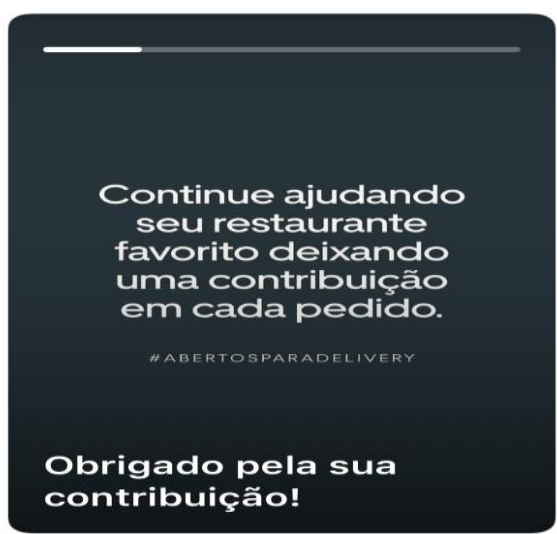

Fonte: Instagram @rappibrasil, 11 de maio de 2021 Fonte: Instagram @ubereats_br, 20 de maio de 2020

Observamos a partir da amostra de anúncios acima que a empresa Ifood explora o sentido metafórico dos dois itens léxicos, o que não ocorre sempre nos anúncios das outras duas empresas. Isso nos permite observar uma maior preocupação no que se refere aos recursos estilísticos das construções de seus anúncios.

Tabela 1. Ocorrências dos itens léxicos icônicos

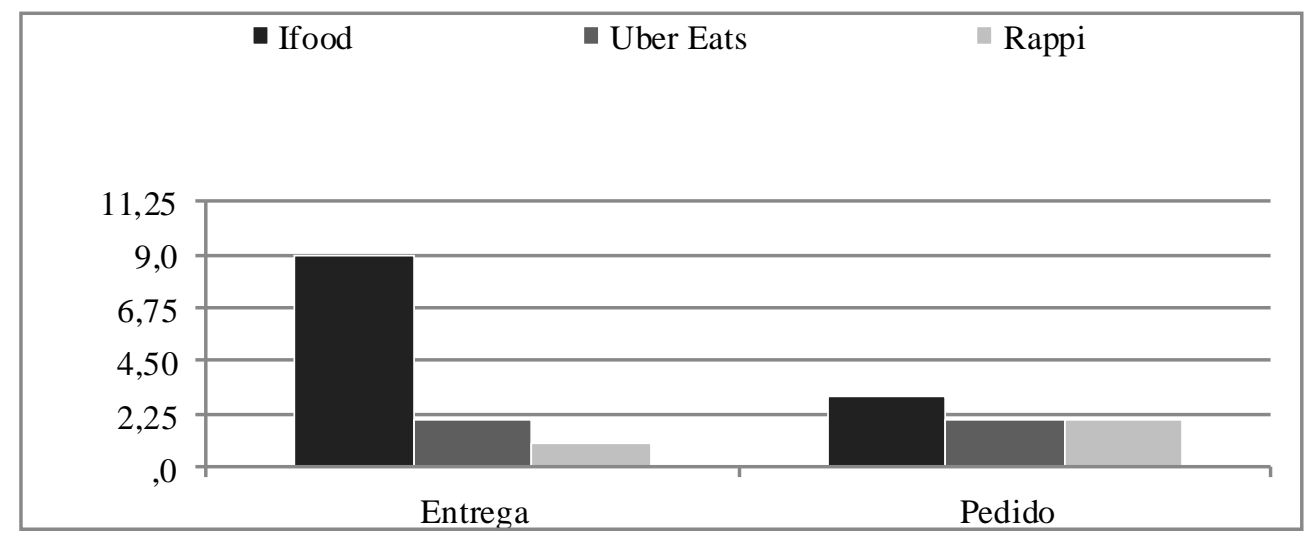

$\mathrm{Na}$ tabela acima, pode-se comprovar tal constatação, observando as baixas ocorrências dos dois principais itens léxicos nos anúncios da Uber Eats e da Rappi, em oposição a um número maior da empresa Ifood. 


\section{ESTILÍSTICA DA FRASE E ICONICIDADE DIAGRAMÁTICA}

A empresa Ifood divulgou a hashtag - \#ViverÉ - em sua página do Instagram, @ifoodbrasil, e contratou algumas celebridades da internet para divulgá-la. O intuito era difundir essa frase para seu público-alvo e fazer com que as pessoas a completassem das maneiras mais criativas possíveis; além de interiorizarem as sugestões de "como viver a vida”, propostas pela página deles do Instagram. Henriques (2018, p. 105) nos faz refletir que "a sintaxe é a análise das relações e que a estilística dos mecanismos da frase pode favorecer o impulso da expressividade". Está aí uma dupla perfeita, afinal, quem não quer experimentar relações expressivas na hora de construir suas mensagens e se comunicar?

Figura 19- Campanha \#ViverÉ.

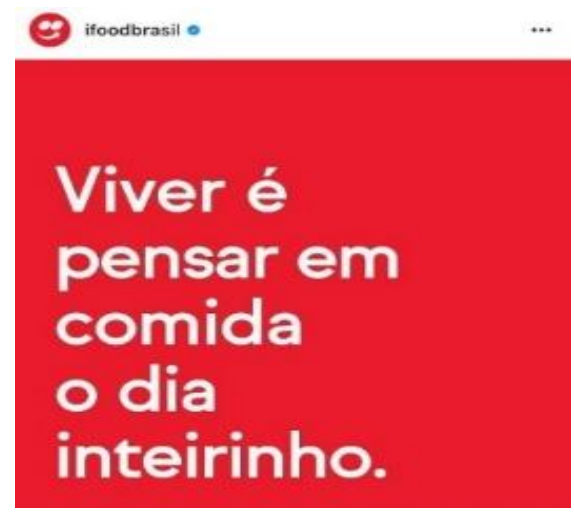

Fonte: Instagram @ifoodbrasil, 15 de outubro de 2020
Figura 20- Campanha \#ViverÉ.



Fonte: Instagram @ifoodbrasil, 27 de janeiro de 2021.

Figura 21- Campanha \#ViverÉ

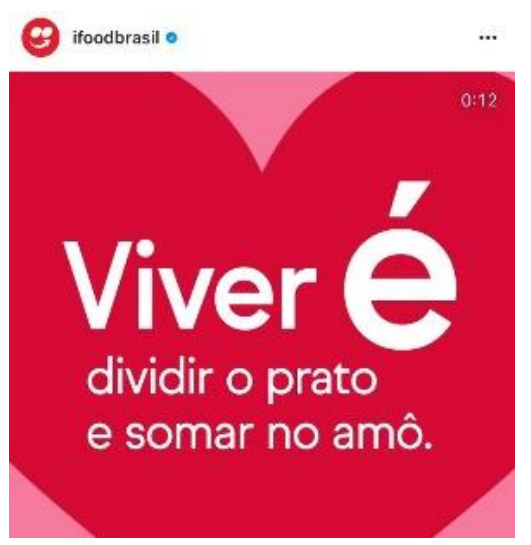

Fonte: Instagram @ifoodbrasil, 12 de fevereiro de 2021. 
A partir da observação dos anúncios, pode-se notar claramente uma preferência sintático-estilística da empresa Ifood pelas orações subordinadas substantivas predicativas reduzidas de infinitivo. Essa escolha baseia-se não só na concisão como também na expressiva e objetiva firmeza contida nessas orações, pois o verbo "ser" ultrapassa a barreira da indecisão, mira na assertividade e trabalha diretamente no cerne da questão, afastando eventuais ideias dubitáveis. Devido a sua precisão, esse mecanismo linguístico torna-se, portanto, um artifício precioso para a marca. Prova disso é a recorrência dessa estrutura frasal em suas propagandas.

Segundo Bechara (2015, p. 530), "o emprego de reduzidas e desenvolvidas e vice-versa, quando feito com arte e bom gosto, permite ao escritor variados modos de tornar o estilo conciso, não acumulado de quês e outros transpositores, assim, elegantes", e para completar esse pensamento, rumo a um encadeamento de ideias, Azeredo (2018, p. 345) afirma que “a versatilidade do verbo de ligação 'ser' permite, até mesmo, que um mais variado grupo de estruturas participe da relação sujeitopredicado". Diante disso, far-se-á uma comparação entre as orações predicativas desenvolvidas e reduzidas, retiradas das propagandas para uma análise sintáticoestilística:

Figura 22- Campanha \#ViverÉ



Figura 23- Campanha \#ViverÉ



Fonte: Instagram @ifoodbrasil, 18 de janeiro de 2021 Fonte: Instagram @ifoodbrasil, 11 de outubro de 2020

22. Propaganda original: "Viver é curtir esse carinho em forma de descontinhos".

Oração desenvolvida: "Viver é para quem curte esse carinho em forma de descontinhos". 
23. Propaganda original: "Viver é sdds de se juntar."

Oração desenvolvida: "Viver é para quem tem saudade de se juntar."

Além da oração reduzida expressar concisão e objetividade, sua estrutura transpõe o muro da contestabilidade, tornando-se, assim, uma verdade universal para quem ouve "viver é curtir [...]". Então, pode-se pressupor que, ao pé da letra, caso não se viva dessa maneira descrita pela propaganda, não se vive corretamente. Já em "Viver é para quem curte [...]", abre-se brecha para interpretar que existem aqueles que não curtem. Obtém-se uma estrutura que expressa uma seleção daqueles que curtem e daqueles que não curtem, oferecendo uma opção para aqueles que, porventura, não queiram viver dessa maneira. Com base nisso, conclui-se que a brecha existente no segundo exemplo inexiste no primeiro, o que possivelmente contribuiu para que a empresa escolhesse essa estrutura em detrimento da outra.

A análise do exemplo 2 se encaixa perfeitamente com a do exemplo 1, uma vez que se observa o mesmo uso preferencial pela oração reduzida. Na propaganda original, observa-se a omissão proposital do verbo "ter", evidenciando ainda mais o sentimento expresso pelo termo "sdds" (saudades), que foi escrito em sua forma abreviada para remeter à comunicação no âmbito da internet. Atendo-se ao pensamento de Marcuschi (2016, p. 35) “[...] é possível ser coerente e coeso sem seguir linearmente e na superfície [...] na língua nem tudo é transparente [...] muitas coisas só se constroem na relação com o leitor no ato da escrita voltada para a interação [...]". Ou seja, a linguagem humana é flexível, não se constitui de forma peremptória, realiza-se por associações e pelo contexto em que está inserida.

Segundo Simões (2009, p. 96), "definimos iconicidade diagramática como a qualidade atinente ao projeto visual ou sonoro do texto e à estruturação dos sintagmas". Podemos, assim, perceber como as frases acima analisadas possuem alto potencial de iconicidade diagramática. Dos cinco anúncios analisados nesta seção, quatro exploram um projeto visual da construção sintática em que o verbo "viver" da oração principal está em destaque com letras maiores que a oração subordinada, e o verbo de ligação "ser", em sua forma conjugada na terceira pessoa do presente do indicativo - "é" -, 
aparece ainda maior. Isso nos permite inferir a intenção do anunciante em suscitar uma reflexão sobre a vida, sobre a dualidade entre SER/EXISTIR, em tempos sombrios de pandemia com milhares de vítimas fatais.

Para Cressot (1980, p. 16), "podemos proceder de um fato linguístico, procurar a intenção que a ele se associa, inquietarmo-nos com as razões profundas que a justificam, esclarecer outros fatos vagamente equivalentes e o pormenor que levou à escolha". Uma vez entendida as razões que motivaram essa preferência, conclui-se que a reincidência da estrutura gramatical escolhida pela empresa não é coincidência, é estratégia. A língua não é um mero artefato acessório, não está à margem, pelo contrário, está no centro das relações humanas. Não existem coincidências na língua, o que existem são escolhas dotadas de significados.

\section{CONSIDERAÇÕES FINAIS}

Num mundo de cada vez mais incertezas, mais opiniões/conselhos alheios e mais perguntas do que respostas, a assertividade faz a diferença. A certeza imposta pela fala/escrita numa oração afirmativa traz um sentimento de tranquilidade e de estar fazendo a coisa certa, tira o interlocutor do limbo do questionamento e da imposição e o eleva a um lugar de plenitude que a certeza proporciona. Em anúncios publicitários, esse recurso é ainda mais valioso.

Observa-se, portanto, que a empresa Ifood inovou em suas publicidades, blindou-se de assertividade ao se mostrar como uma espécie de guru absoluto para o interlocutor, por meio das orações predicativas, jogou com as palavras, elevou a estética dos anúncios tradicionais e se superou com os curiosos recursos estilísticos. O intuito de toda essa inovação é se aproximar dos jovens - público-alvo que detém mais intimidade com aparelhos eletrônicos e suas facilidades, logo potenciais clientes.

As empresas Rappi e Uber Eats se utilizaram de uma estratégia mais conservadora. Preferiram continuar na zona de conforto, utilizando verbos no imperativo, ferramentas que sempre funcionaram; no entanto, foi deficitária no quesito inovação, não mostrando estratégias inovadoras para atrair ainda mais os jovens. Nesse quesito, em se tratando de concorrência pesada, num momento pandêmico em que a demanda é altíssima, apostar nos anúncios publicitários inovadores é um diferencial. 
Por isso, é crucial frisar que a intenção deste trabalho não foi impor juízo de valor no uso deste ou daquele modo verbal, mas mostrar que, no gênero injuntivo, não há apenas o recurso do verbo no imperativo, existem outras formas de fazer propaganda. O terreno da linguagem é fértil, quanto mais os anunciantes tiverem conhecimento e consciência do poder e da plasticidade da língua, mais frutos colherão.

\section{Referências}

ANTUNES, Irandé. Muito além da gramática: por um ensino de línguas sem pedras no caminho. São Paulo: Parábola, 2007.

Aula de Português: encontro e interação. São Paulo: Parábola, 2003.

AZEREDO, José Carlos de. Gramática Houaiss da Língua Portuguesa. São Paulo: Publifolha, 2018.

A Linguística, o Texto e o Ensino da Língua. São Paulo: Parábola, 2018.

BAKHTIN, Mikhail. Marxismo e Filosofia da Linguagem. São Paulo: Hucitec, 1995.

CRESSOT, Michel. O estilo e as suas técnicas. Lisboa: Edições 70, 1980.

CERVO Amado Luiz; BERVIAN Pedro Alcino. Metodologia científica. São Paulo: Prentice Hall, 2002.

FARACO, Carlos Alberto. Linguagem e Diálogo: as ideias linguísticas do círculo de Bakhtin. São Paulo: Parábola, 2009.

FIORIN, José Luiz. Introdução ao pensamento de Bakhtin. São Paulo: Contexto, 2018.

GALLIANO, Alfredo Guilherme. O método científico: teoria e prática. São Paulo: Harbra, 1986.

GARCIA, Moacir Othon. Comunicação em Prosa Moderna: aprenda a escrever, aprendendo a pensar. Rio de janeiro: FGV, 2010.

HENRIQUES, Claudio Cezar. Estilística e Discurso: Estudos produtivos sobre texto e expressividade. Rio de Janeiro: Alta Books, 2018.

MARCUSCHI, Luiz Antônio. Linguística de texto: o que é e como se faz? São Paulo: Parábola, 2016.

MARTINS, Nilce Sant'anna. Introdução à Estilística: A expressividade da Língua Portuguesa. São Paulo: T.A. EDUSP, 2012. 
SIMÕES, Darcilia. Para uma teoria da iconicidade verbal. Campinas, SP: Pontes Editores, 2019.

Recebido em: 31/08/2021

Aceito em: 13/12/2021 